\title{
Prevalence of Atrial Fibrillation in Korean Population
}

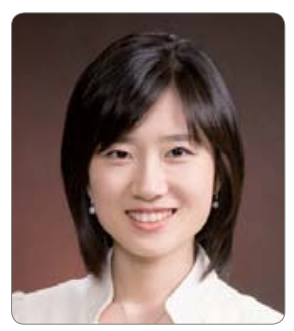

So-Ryoung Lee

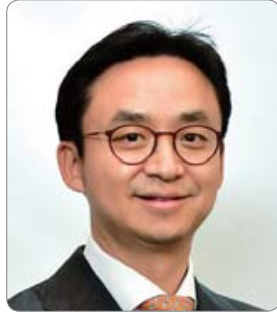

Eue-Keun Choi
So-Ryoung Lee MD1; Eue-Keun Choi, MD PhD2

${ }^{1}$ Division of Cardiology, Department of Internal Medicine, Soon Chun Hyang University Hospital Seoul, Seoul, Republic of Korea

${ }^{2}$ Division of Cardiology, Department of Internal Medicine, Seoul National University Hospital, Seoul, Republic of Korea
Received: December 6, 2017

Revision received: December 25, 2017

Accepted: December 27, 2017

Correspondence: Eue-Keun Choi, MD, PhD

Department of Internal Medicine, Seoul National

University Hospital 101 Daehak-ro, Jongno-gu,

Seoul, 03080, Republic of Korea

Tel: +82-2-2072-0688 Fax: +82-2-762-9662

E-mail: choiek17@snu.ac.kr

\begin{abstract}
Atrial fibrillation (AF) is the most common cardiac arrhythmia in clinical practice and has been a major public health problem. The prevalence of AF globally has been reported to range from $0.4 \%$ to $2 \%$ in the adult population; however, the prevalence widely varies depending on the study population. Although AF prevalence in Asian population is about $1 \%$ lower than that in European and North American population, the number of AF patients in Asia is rapidly increasing concomitant with the increased aging of the population. However, previous studies that reported AF epidemiology in the Korean population are limited. According to a recent report based on the national health claims database, prevalence of AF in 2015 was $0.7 \%$ in the entire Korean adult population and showed a continuous increase with population aging. Additionally, among patients with $\mathrm{AF}$, mean $\mathrm{CHA}_{2} \mathrm{DS}_{2}$-VASc score was significantly increased and the number of high thromboembolic risk patients has increased over time. Although oral anticoagulation $(\mathrm{OAC})$ prescription in AF patients increased from $35 \%$ to $51 \%$, especially after introduction of non-vitamin $\mathrm{K}$ antagonist anticoagulants, a substantial proportion of Korean patients with AF still remain undertreated. In this review, we aimed to summarize temporal changes in the prevalence and incidence of $\mathrm{AF}$ and to evaluate the thromboembolic risk in patients with AF. In addition, we also discussed the utilization of OAC therapy in patients with AF in Korean population.
\end{abstract}

Key Words: - Atrial Fibrillation - Epidemiology - Stroke - Oral Anticoagulation 


\section{Introduction}

Atrial fibrillation (AF) is the most common cardiac arrhythmia in clinical practice. ${ }^{1} \mathrm{AF}$ is a well-known independent risk factor for ischemic stroke, and globally, the prevalence of AF has continuously increased with the population aging; thus it has become a major public health problem. ${ }^{2-4}$ The estimated prevalence of AF has been reported to range from $0.4 \%$ to $2 \%$ in the adult population; however, this varies widely depending on the study population. ${ }^{5}$ Information on clinical epidemiology of AF has been derived from studies that have mainly included the population in Europe and the United States. Although Asian countries are known to have about $1 \%$ lower prevalence of $\mathrm{AF}$ than that in Europe and the United States, the number of Asian patients with AF is rapidly growing as the population ages. ${ }^{6,7}$ Studies that reported AF epidemiology in Asian population are limited, but recently, corresponding to the increase in clinical research based on national health claim database, especially in Asian countries such as Taiwan and Korea, more accurate AF epidemiology data have been published. ${ }^{8,9}$

While the global burden of AF has been increased over time, the management of AF has also greatly evolved. For stroke prevention in $\mathrm{AF}$, the $\mathrm{CHA}_{2} \mathrm{DS}_{2}$-VASc score was introduced to assess thromboembolic risk and a non-vitamin $\mathrm{K}$ antagonist oral anticoagulant (NOAC) has become available as an effective and safe alternative to warfarin. ${ }^{10-12}$ Although appropriate anticoagulation therapy could reduce the risk of stroke by $64 \%$ and mortality by $26 \%$ in patients with AF, many patients who need anticoagulation therapy for stroke prevention still remain untreated or undertreated. ${ }^{3-16}$ Additionally, most of the studies reporting the utilization of oral anticoagulation $(\mathrm{OAC})$ therapy in patients with $\mathrm{AF}$ are based on Western population. There are a few studies reporting the $\mathrm{OAC}$ prescription pattern therapy in Asian population. ${ }^{16-18}$

Therefore, we aimed to summarize temporal changes in the prevalence and incidence of AF in Korean population. Furthermore, we evaluated the thromboembolic risk in patients with $\mathrm{AF}$ and the utilization of OAC therapy for stroke prevention in Korean AF patients.
Prevalence and incidence of atrial fibrillation in entire Korean population

In Western countries, the incidence and prevalence of AF has consistently increased over the past decades, with the current estimated prevalence of AF at approximately $2 \% .^{1,19}$ The prevalence of $\mathrm{AF}$ increases with age, ranging from $0.1 \%$ among patients younger than 55 years to $9.0 \%$ among patients 80 years or older. ${ }^{19}$ Studies reporting the AF epidemiology in Korean population are limited. From two different community-based cohort studies, the prevalence of AF reported in the early 2000s was $0.4 \%$ in population aged $40-69$ years and $0.7 \%$ in those older than 40 years. ${ }^{20,21}$ Based on a sample cohort study from the National Health Insurance Service database, the overall incidence of AF was reported to be 1.5 to 2.87 per 100 person-years and prevalence of AF was $1.38 \%$ in $2013.22,23$ Although previous reports provided insights into the AF epidemiology in Korean population, the sample sizes were relatively small; hence, there was no information on temporal trends of AF epidemiology and the association between population aging and the temporal change of AF epidemiology was not reported. Recently, we published temporal trends in the incidence and prevalence of AF in entire Korean population between 2008 and 2015 based on the national health claims database established by the National Health Insurance Service (NHIS) of Korea. ${ }^{8}$ The definition of the incidence and prevalence of AF is as follows. The annual incidence of AF was calculated as the number of patients with newly diagnosed AF for each year divided by the total personyears at risk among all individuals of that year who did not have AF during the last 3-year period. ${ }^{8}$ The annual prevalence of AF was calculated as the number of patients with AF divided by the total population of each year. ${ }^{8}$ Briefly, AF incidence and prevalence gradually increased, and both significantly increased with older age. AF was defined as patients having at least one discharge diagnosis with $\mathrm{AF}$ or patients who were at least twice diagnosed with AF in an outpatient clinic. During the 8-years, the incidence of $\mathrm{AF}$ increased to >1.12-fold as follows: from 15.34 to 17.14 per 10,000 person-years $(p<0.001)$ (Figure 1A). The overall incidence rates per 10,000 person-years were 3.0, 6.0, 14.3, 33.7, and 67.4 per 10,000 person-years among those aged 30-39, 40-49, 50-59, 60-69, and 70-79 years, respectively. The AF incidence in 
A

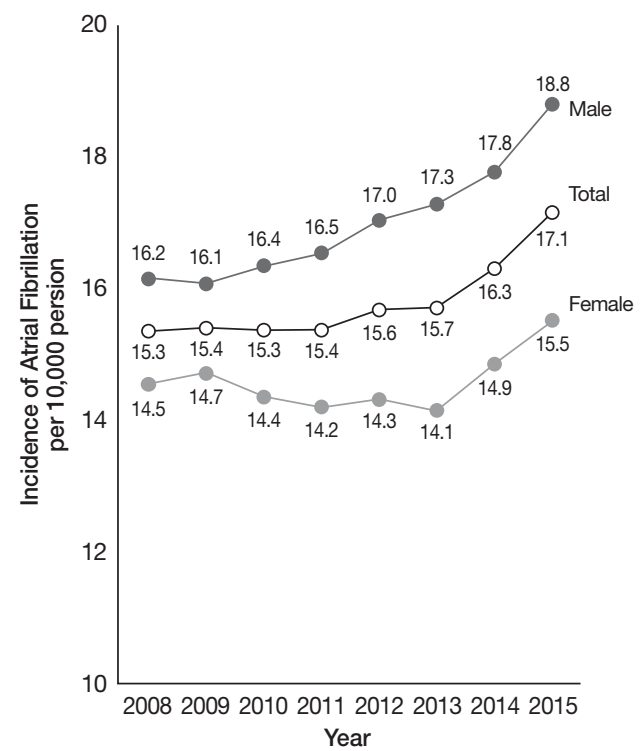

B

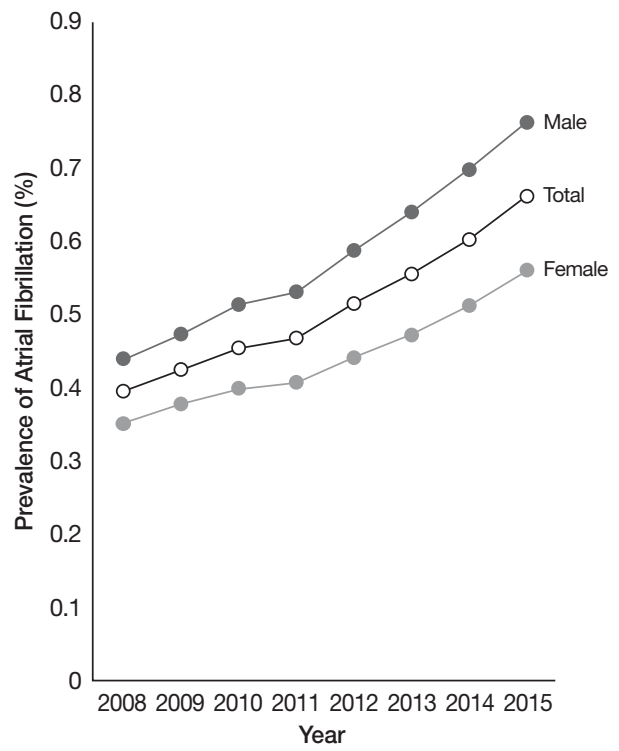

Figure 1. Incidence and prevalence atrial fibrillation (AF) in Korea between 2008 and 2015. Reprinted from Lee et al. ${ }^{8}$ with permission. (A) Annual incidence of AF stratified by sex. (B) annual prevalence of AF stratified by sex.

those aged $>80$ years was 100.4 per 10,000 person-years. Recently, Korean population is aging faster than any other developed countries, which might be reflected in the gradual increase of AF incidence. Also, there are several possible explanations for increasing incidence of AF except for the natural increase of AF in Korea. The "AF awareness" in Korea has been increased, especially after introduction of NOAC, which could impact the incidence of AF. Compared to warfarin era, the risk of AF on stroke and the benefit of stroke prevention in high-risk population was more emphasized to general population and physicians due to the convenience and safety of NOAC. The strict reimbursement criteria of NOAC prescription, i.e. mandatory of AF diagnosis code, which made physicians not to omit the AF diagnosis code. Lastly, the health-check up in Korea became more common, which could detect asymptomatic undiagnosed AF in general population.

Furthermore, the prevalence of AF consistently increased by 1.7-fold, from $0.40 \%$ in 2008 to 0.67 in 2015 (Figure 1B). In $2015,276,246$ subjects $(0.67 \%$ of the adult population aged $\geq 20$ years) had AF. Men had a significantly higher prevalence of AF than women. AF prevalence increased with age, ranging from $0.03 \%$ among individuals aged $\geq 60$ years in 2008 and $2.28 \%$ had
AF in 2015. A linear increase in AF prevalence was observed from age 50-59 years to $>80$ years. The annual increase was more prominent in the older age group.

The prevalence of AF in the entire Korean population was $0.67 \%$, lower than that in the Western population. ${ }^{15,19}$ However, this prevalence is closer to that reported in China (0.8-0.9\%), Japan (0.9\%), and Taiwan (1.07\%). ${ }^{6,94,25}$ An important finding is that the increases in AF incidence and prevalence were primarily due to the increase in the elderly population. This result was in accordance with that of previous studies, which reported that the incidence and prevalence of AF have been increasing with population aging and the increasing prevalence of comorbidities. ${ }^{1,5-7,19}$

\section{Prevalence of atrial fibrillation based on geographical} distribution and socioeconomic status in Korean population

Considering the increasing burden of AF in Korea, appropriate anticoagulation therapy in AF patients is an important issue to improve clinical outcomes. However, many AF patients do not feel any need for stroke prevention because of absence of 
A

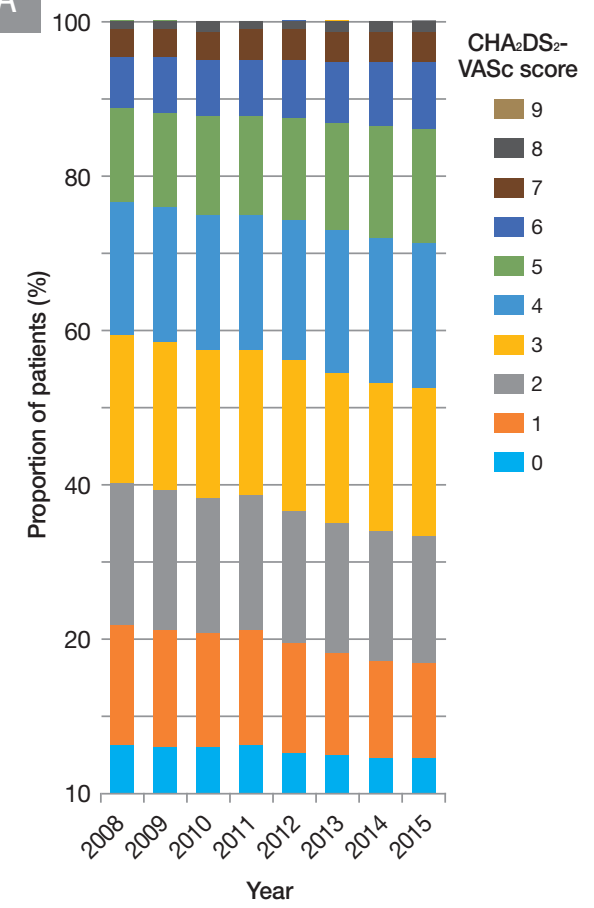

B

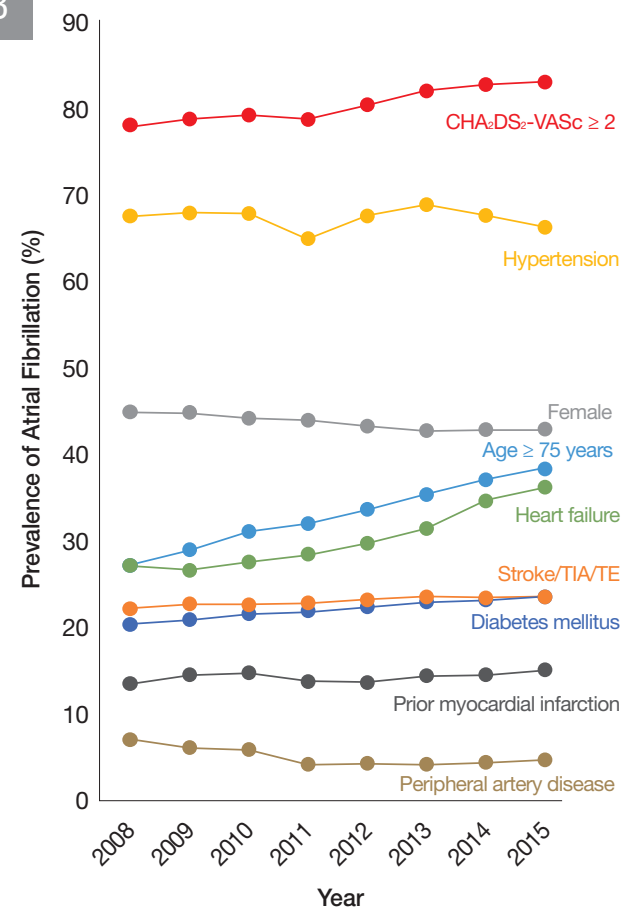

Figure 2. Temporal changing trends of estimated thromboembolic risk in patients with atrial fibrillation. Reprinted from Lee et al. ${ }^{8}$ with permission. (A) Distribution of $\mathrm{CHA}_{2} \mathrm{DS}_{2}$-VASc scores in patients with atrial fibrillation over time. (B) Temporal changes of components of $\mathrm{CHA}_{2} \mathrm{DS}_{2}$-VASc scores between 2008 and 2015.

symptoms, and unfortunately, some of these patients present with stroke as an initial manifestation of $\mathrm{AF}^{26,27}$ It is very important to identify high-risk population using appropriate screening program for AF detection, and initiate adequate OAC therapy based on annual stroke risk. Regional and socioeconomic circumstance could influence the screening and management of AF. There are few population-based studies reporting the regional and socioeconomic differences in AF prevalence. Using 2015 National Health Insurance Service database, we performed a cross-sectional analysis of Korean adults to evaluate the AF epidemiology in different geographical location based on residence and income levels. ${ }^{28}$ Overall prevalence of AF in suburban/rural regions was significantly higher than that observed in urban regions $(0.72 \%$ vs. $0.61 \%$, respectively, $p<0.001)$. According to income level, AF prevalence showed J-shaped curve. Income level was categorized based on the monthly health insurance premiums paid and divided the population into 21 levels. The lowest income population was categorized as Medical Aid beneficiaries (3\% of total population) and the rest of population divided into 20 levels ranging from group 1 (lowest) to group 20 (highest). An extremely low-income group, represented as Medical Aid beneficiaries group, showed significantly higher prevalence of AF (1.77\%). From group 1 to 7 , AF prevalence gradually decreased from $0.76 \%$ to $0.44 \%$ and increased until group 20 from $0.44 \%$ to $1.06 \%$

There were several factors that affected the prevalence of AF in a particular population. The co-morbidities that predisposed to AF, such as old age, hypertension, diabetes, and heart failure, corresponded to the pattern of AF prevalence. In addition, the disparities in availability of healthcare service by regions and income levels can affect the diagnosis of AF. Although the etiology of stroke/transient ischemic attack (TIA)/systemic thromboembolism (TE) was not fully identified in our study, the prevalence of stroke/TIA/TE correlated with the AF prevalence by both geographical regions and income levels. Applying appropriate AF screening program for early detection of $\mathrm{AF}$ particularly in the population with a greater predisposition to the development AF, improving in access to general health care, and utilizing of adequate OAC treatment is important for stroke prevention. 
Estimated thromboembolic risk using the $\mathrm{CHA}_{2} \mathrm{DS}_{2}-$

\section{VASc score in Korean population}

According to the current guidelines, the stroke risk of AF patients was estimated based on the $\mathrm{CHA}_{2} \mathrm{DS}_{2}$-VASc score. ${ }^{10.29 .31}$ $\mathrm{CHA}_{2} \mathrm{DS}_{2}$-VASc score was calculated by assigning 1 point for age between 65-74 years, female sex, and the presence of hypertension, diabetes, heart failure, and vascular disease (prior myocardial infarction (MI), presence of peripheral artery disease (PAD) or presence of aortic plaque), and adding 2 points for a prior stroke/TIA/TE or age of $\geq 75$ years. ${ }^{10}$ The proportion of the AF patients with $\mathrm{CHA}_{2} \mathrm{DS}_{2}$-VASc score of $\geq 2$, who were strongly recommended for OAC treatment for stroke prevention, increased from 2008 to 2015 (Figure 2A). ${ }^{8}$ In 2015, 83.2\% of patients with $\mathrm{AF}$ were identified to be at high risk for stroke $\left(\mathrm{CHA}_{2} \mathrm{DS}_{2}\right.$-VASc score of $\left.\geq 2\right)$. The main reason for increase in the high-risk AF population for stroke is the aging of AF patients. The proportion of elderly people aged $\geq 75$ years increased from $27.4 \%$ to $38.4 \%$ during the last 8 years (Figure $2 \mathrm{~A}$ ). Moreover, increasing prevalence of comorbidities, such as diabetes and heart failure, also led to an increase in high-risk population (Figure 2B). These factors ultimately result in an elevation of $\mathrm{CHA}_{2} \mathrm{DS}_{2}$-VASc score. Compared with the national registry of Denmark, almost $80 \%$ of patients with $\mathrm{AF}$ were defined as having a $\mathrm{CHA}_{2} \mathrm{DS}_{2}$ VASc scores of $\geq 2 .{ }^{32}$ Like Korean and Danish data, in a nationwide database of Taiwan, $84.4 \%$ of AF patients were classified as those having $\mathrm{CHA}_{2} \mathrm{DS}_{2}$-VASc scores of $\geq 2 .{ }^{83233}$

$\mathrm{CHA}_{2} \mathrm{DS}_{2}-\mathrm{VASc}$ scores were derived and validated from Western cohorts, and the applicability of $\mathrm{CHA}_{2} \mathrm{DS}_{2}$-VASc score to Asian populations has been debated. ${ }^{10,32}$ In previous studies, the annual stroke risk in Asian populations varied from that reported from Western populations. ${ }^{3437}$ Studies validating $\mathrm{CHA}_{2} \mathrm{DS}_{2}$-VASc score in Korean population is limited. Recently, Kang et al. and Kim et al. published the validation data of $\mathrm{CHA}_{2} \mathrm{DS}_{2}$-VASc score for stroke risk assessment in Korean population. ${ }^{38,39}$ In Korean population, the $\mathrm{CHA}_{2} \mathrm{DS}_{2}$-VASc score showed good performance (Table 1). The incidence rates (per 100 personyears) of ischemic stroke or composite thromboembolic events

Table 1. Annual stroke rate in Korean AF population and other cohorts stratified by $\mathrm{CHA}_{2} \mathrm{DS}_{2}-\mathrm{VASc}$ score

\begin{tabular}{|c|c|c|c|c|c|c|c|c|}
\hline \multirow{3}{*}{$\begin{array}{l}\mathrm{CHA}_{2} \mathrm{DS}_{2-} \\
\text { VASc score }\end{array}$} & \multirow{2}{*}{$\begin{array}{l}2010 \text { ESC } \\
\text { guideline }{ }^{11,40}\end{array}$} & \multicolumn{3}{|c|}{$\begin{array}{l}\text { Korean National Health Insurance Service } \\
\text { Sample Cohort Database }\end{array}$} & \multirow{2}{*}{ Taiwann } & \multirow{2}{*}{$\operatorname{Japan}^{42}$} & \multirow{2}{*}{$\begin{array}{l}\text { Euro Heart } \\
\text { Survey }{ }^{10}\end{array}$} & \multirow{2}{*}{ Denmark ${ }^{32}$} \\
\hline & & Kang et al. ${ }^{38}$ & Kim et al. ${ }^{39}$ & Kim et al..$^{39}$ & & & & \\
\hline & $\begin{array}{c}\text { Ischemic } \\
\text { stroke/systemic } \\
\text { embolism }^{*}\end{array}$ & $\begin{array}{l}\text { Ischemic } \\
\text { stroke }\end{array}$ & $\begin{array}{l}\text { Ischemic } \\
\text { stroke }^{\dagger}\end{array}$ & $\begin{array}{c}\text { Ischemic } \\
\text { stroke/systemic } \\
\text { embolism }^{\dagger}\end{array}$ & $\begin{array}{l}\text { Ischemic } \\
\text { stroke }\end{array}$ & $\begin{array}{l}\text { Ischemic } \\
\text { stroke }\end{array}$ & $\begin{array}{l}\text { Ischemic } \\
\text { stroke/systemic } \\
\text { embolism }\end{array}$ & $\begin{array}{c}\text { Ischemic } \\
\text { stroke/systemic } \\
\text { embolism }\end{array}$ \\
\hline 0 & 0.0 & 0.61 & $0.26^{\ddagger}$ & $0.29^{\ddagger}$ & 1.15 & 0.53 & 0 & 0.66 \\
\hline 1 & 1.3 & 0.92 & $1.18^{\S}$ & $1.35^{\S}$ & 2.11 & 0.55 & 0.6 & 1.45 \\
\hline 2 & 2.2 & 2.10 & 2.21 & 2.35 & 3.39 & 1.11 & 1.6 & 2.92 \\
\hline 3 & 3.2 & 3.49 & 2.88 & 3.04 & 3.89 & 1.38 & 3.9 & 4.28 \\
\hline 4 & 4.0 & 5.14 & 5.34 & 5.76 & 4.61 & 1.52 & 1.9 & 6.46 \\
\hline 5 & 6.7 & 9.53 & 6.54 & 6.76 & 5.12 & 4.43 & 3.2 & 9.97 \\
\hline 6 & 9.8 & 17.35 & 9.50 & 9.77 & 5.18 & 4.07 & 3.6 & 12.52 \\
\hline 7 & 9.6 & 41.44 & $9.97 "$ & $10.21^{\| \prime}$ & 6.22 & 1.56 & 8.0 & 13.96 \\
\hline 8 & 6.7 & 37.48 & & & 7.98 & 6.95 & 11.1 & 14.10 \\
\hline 9 & 15.2 & 48.17 & & & 10.50 & $>100$ & 100 & 15.89 \\
\hline
\end{tabular}

Adjusted to WFR use; tadjusted for aspirin use; ${ }^{C}$ CHA2DS2-VASc score of 0 included male with 0 or female with $1 ;{ }^{\circledR} \mathrm{CHA}_{2} \mathrm{DS}_{2}$-VASc score of 1 included male with 1; "CHA $2 \mathrm{DS}_{2}$-VASc score of $\geq 7$. 
showed a clear correlation with $\mathrm{CHA}_{2} \mathrm{DS}_{2}$-VASc score. The risk of stroke stratified by $\mathrm{CHA}_{2} \mathrm{DS}_{2}$-VASc scores in Korean population was comparable to that reported in previous studies (Table 1). ${ }^{10,11,32,38-42}$ In particular, $\mathrm{CHA}_{2} \mathrm{DS}_{2}$-VASc score welldiscriminated the patients who were truly at low risk for stroke, and this was a meaningful finding. ${ }^{38,39}$ In NOAC era, the efficacy and safety of OAC treatment improved and the threshold for OAC treatment in AF patients for stroke prevention has been lowered from an annual stroke rate of $1.7 \%$ with warfarin to $0.9 \%$ with NOACs. ${ }^{12,43}$ Therefore, $\mathrm{CHA}_{2} \mathrm{DS}_{2}$-VASc score is useful tool for identifying patients at low risk for whom OAC treatment has no net clinical benefit in the Korean AF population. . $^{38,39,44}$

\section{Antithrombotic therapy for stroke prevention in Korean patients with atrial fibrillation}

Although there are clear benefits of OAC therapy for stroke prevention in high-risk AF patients, OAC is still underused in many patients with AF, particularly in the warfarin era. ${ }^{12,45-47}$ The narrow therapeutic range, needs of frequent monitoring/dose adjustments, and interactions with food or drug have made physicians and patients reluctant to use warfarin. ${ }^{45}$ The landscape of stroke prevention in AF patients changed with the availability of NOACs. NOACs offer better efficacy, safety, and convenience, compared to warfarin. ${ }^{12}$ Recently, we have reported the improved effectiveness and safety of NOAC over warfarin in Korean patients with $\mathrm{AF}^{48}$ Compared to warfarin, all three NOACs (dabigatran, rivaroxaban, and apixaban) showed similar risk of ischemic stroke and a lower risk of intracranial hemorrhage. Furthermore, recent changes in AF guidelines, which favor NOAC use rather than warfarin use in high-risk AF patients and discourage aspirin prescription in low-risk AF patients, influenced the OAC prescription pattern in real world. ${ }^{11,29,30}$ In 2016 European society of cardiology AF guidelines, OAC treatment is recommended for all male AF patients with a $\mathrm{CHA}_{2} \mathrm{DS}_{2}$-VASc score $\geq 2$ and all female patients with a $\mathrm{CHA}_{2} \mathrm{DS}_{2}-\mathrm{VASc}$ score $\geq$ $3 .^{30}$ Further, in male AF patients with a $\mathrm{CHA}_{2} \mathrm{DS}_{2}$-VASc score of 1 and female patients with $\mathrm{CHA}_{2} \mathrm{DS}_{2}$-VASc score of 2 , OAC should be recommended considering individual characteristics and patient preferences. ${ }^{30}$ Despite these major changes for stroke prevention in AF patients, little contemporary data is available about the changes of utilization of antithrombotic therapy patterns, particularly in Asian population. ${ }^{1416}$

We recently described temporal changes and the current state of antithrombotic therapy in Korean patients with AF, including the era of NOACs. ${ }^{18}$ In Korea, dabigatran was introduced in 2011, rivaroxaban in 2012, and apixaban in 2013. Edoxaban was introduced in Korea in 2016 and, thus, was not included this study. There were special considerations on the medical insurance imbursement policy of NOAC prescription for stroke prevention in AF patients. In 2013, NOAC use for stroke prevention in AF patients was approved only for patients in whom warfarin treatment failed, such as critical bleeding events or labile international normalized ratio values, and $\mathrm{CHA}_{2} \mathrm{DS}_{2}-\mathrm{VASc} \geq 2$. In 2015, reflecting the updated results of randomized controlled clinical trials for NOACs and AF management guidelines on antithrombotic therapy in patients with AF, NOAC use in Korea was more widely approved in patients with $\mathrm{AF}$ and a $\mathrm{CHA}_{2} \mathrm{DS}_{2}$ VASc $\geq 2$ without any conditional terms..$^{12,29,31,49}$ Using the national health claims database between 2008 and 2015, AF patients with antithrombotic therapy were categorized into four treatment groups: no therapy, aspirin only, vitamin $\mathrm{K}$ antagonist (VKA) \pm aspirin as the VKA group, and $\mathrm{NOAC} \pm$ aspirin as the NOAC group.

Among the total study population, approximately $20 \%$ of patients did not receive any antithrombotic therapy. Aspirin use gradually decreased and OAC treatment gradually increased over the 8 -year study period. The majority of patients $(78.2 \%$ in 2008 and $83.2 \%$ in 2015) who required OAC treatment were classified as high stroke risk category based on $\mathrm{CHA}_{2} \mathrm{DS}_{2}$-VASc score of $\geq$ 2. A similar pattern of antithrombotic prescription was observed in patients with $\mathrm{CHA}_{2} \mathrm{DS}_{2}$-VASc score of $\geq 2$. Approximately $17 \%$ of patients were not prescribed any antithrombotic therapy throughout the study period. Aspirin use consistently decreased from $48.2 \%$ to $31.5 \%$, while OAC prescription increased from $34.7 \%$ to $50.6 \%$ from 2008 to 2015 . After wide approval of NOACs in 2015, NOAC prescription increased (25.4\% of patients with $\mathrm{CHA}_{2} \mathrm{DS}_{2}$-VASc score $\geq 2$ and $50.2 \%$ of patients with OAC prescriptions). Nearly one-half of men with $\mathrm{CHA}_{2} \mathrm{DS}_{2}$-VASc score of 1 received aspirin, and patients with an OAC prescription were lower than $30 \%$ throughout the study period. In addition, we found that older age, male sex, history of 
prior stroke/TIA/TE, and presence of comorbidities (hypertension, diabetes, and heart failure) were associated with OAC prescription, whereas female sex, prior MI, presence of $\mathrm{PAD}$, and prior intracranial hemorrhage were associated with OAC non-prescription.

OAC prescription rate widely varies depending on countries and study populations, ranging from $15 \%$ to $80 \%{ }^{45,46}$ The Global Anticoagulant Registry in the FILED-Atrial Fibrillation (GARFIELD-AF) reported a temporal change of OAC prescription patterns in newly diagnosed AF patients based on comparison over sequential cohorts between 2010 and 2015. ${ }^{14}$ The prescription rate of OAC in GARFIELD-AF increased from $57.4 \%$ to $71.1 \%$, and this increment was largely driven by NOAC prescription. Similarly, Global Registry on Long-Term Oral Antithrombotic Treatment in Patients with Atrial Fibrillation (GLORIA-AF) Phase 2 also showed a similar increase in OAC use in the era of NOACs. ${ }^{16}$ Compared to the pre-NOACs era, the proportion of patients with OAC prescription has markedly increased from $68 \%$ to $80 \%$. NOAC accounted for $60 \%$ of total OACs prescribed. Similar findings were observed in Danish nationwide registries. ${ }^{15}$

Compared to the European population, whether in the era of pre- or post-NOACs, a higher proportion of AF patients do not receive $\mathrm{OAC}$ treatment for stroke prevention in the Asian population. ${ }^{16,17}$ In GLORIA-AF, OAC was prescribed in $55.2 \%$ of the total Asian population with AF, and about $50 \%$ of OAC users received NOACs. ${ }^{16}$ Approximately $23.7 \%$ patients were prescribed aspirin, and $20 \%$ of patients did not receive any antithrombotic therapy. ${ }^{16}$ The antithrombotic therapy distribution in 2015 for Korean AF population is similar to that of the Asian population in GLORIA-AF..$^{18}$

The decrease in aspirin use and increase in OAC prescription reflect major changes in the current guidelines in real world practice. ${ }^{29,30,49}$ In keeping with the pivotal major trials and updated guidelines in other societies, the Korean guidelines recommended NOACs or warfarin in patients with $\mathrm{CHA}_{2} \mathrm{DS}_{2}-\mathrm{VASc}$ score $\geq 1 .{ }^{31}$ Although OAC is still underused in 2015, prescription patterns for stroke prevention in patients with AF has changed according to current guidelines. In the current era of NOACs, physicians might initiate OAC treatment earlier and more easily using NOACs without concern about frequent monitoring and dose adjustment. Nevertheless, the proportion of patients without any antithrombotic therapy has not changed over time despite the many changes in guidelines and introduction of NOACs.

\section{Conclusion}

In Korea, the prevalence and incidence of AF has increased gradually over the last several years. Although the $\mathrm{CHA}_{2} \mathrm{DS}_{2}$ VASc score has been validated in Korean patients with AF, there are still substantial numbers of patients who do not receive OAC therapy despite their high stroke risk. Therefore, a more comprehensive understanding of AF epidemiology is necessary to establish prevention and management strategies for AF and consequently improve clinical outcomes of AF patients in the current era.

\section{References}

1) Schnabel RB, Yin $X$, Gona P, Larson MG, Beiser AS, McManus DD, Newton-Cheh C, Lubitz SA, Magnani JW, Ellinor PT, Seshadri S, Wolf PA, Vasan RS, Benjamin EJ, Levy D. 50-year trends in atrial fibrillation prevalence, incidence, risk factors, and mortality in the Framingham Heart Study: a cohort study. Lancet. 2015;386:154-162.

2) Wolf PA, Abbott RD, Kannel WB. Atrial fibrillation as an independent risk factor for stroke: the Framingham Study. Stroke. 1991;22:983-988.

3) Colilla S, Crow A, Petkun W, Singer DE, Simon T, Liu X. Estimates of current and future incidence and prevalence of atrial fibrillation in the population. Am J Cardiol. 2013;112:1142-1147.

4) Krijthe BP, Kunst A, Benjamin EJ, Lip GY, Franco OH, Hofman A, Witteman JC, Stricker BH, Heeringa J. Projections on the number of individuals with atrial fibrillation in the European Union, from 2000 to 2060. Eur Heart J. 2013;34:2746-2751.

5) Rahman F, Kwan GF, Benjamin EJ. Global epidemiology of atrial fibrillation. Nat Rev Cardiol. 2014;11:639-654.

6) Guo Y, Tian Y, Wang H, Si Q, Wang Y, Lip GYH. Prevalence, incidence, and lifetime risk of atrial fibrillation in China: new insights into the global burden of atrial fibrillation. Chest. 2015;147:109-119.

7) Tse HF, Wang YJ, Ahmed Ai-Abdullah M, Pizarro-Borromeo AB, Chiang CE, Krittayaphong R, Singh B, Vora A, Wang CX, Zubaid M, Clemens A, Lim P, Hu D. Stroke prevention in atrial fibrillation - an 
Asian stroke perspective. Heart Rhythm. 2013;10:1082-1088.

8) Lee SR, Choi EK, Han KD, Cha MJ, Oh S. Trends in the incidence and prevalence of atrial fibrillation and estimated thromboembolic risk using the $\mathrm{CHA}_{2} \mathrm{DS}_{2}$-VASc score in the entire Korean population. Int J Cardiol. 2017;236:226-231.

9) Chao TF, Liu CJ, Tuan TC, Chen TJ, Hsieh MH, Lip GYH, Chen SA. Lifetime risks, projected numbers, and adverse outcomes in Asian patients with atrial fibrillation: A report from the Taiwan nationwide AF cohort study. Chest. 2017 Oct 7.pii: S00123692(17)32881-32887.

10) Lip GY, Nieuwlaat R, Pisters R, Lane DA, Crijns HJ. Refining clinical risk stratification for predicting stroke and thromboembolism in atrial fibrillation using a novel risk factor-based approach: the euro heart survey on atrial fibrillation. Chest. 2010;137:263-272.

11) European Heart Rhythm Association; European Association for Cardio-Thoracic Surgery, Camm AJ, Kirchhof P, Lip GY, Schotten U, Savelieva I, Ernst S, Van Gelder IC, Al-Attar N, Hindricks G, Prendergast B, Heidbuchel H, Alfieri O, Angelini A, Atar D, Colonna P, De Caterina R, De Sutter J, Goette A, Gorenek B, Heldal M, Hohloser SH, Kolh P, Le Heuzey JY, Ponikowski P, Rutten FH. Guidelines for the management of atrial fibrillation: the Task Force for the Management of Atrial Fibrillation of the European Society of Cardiology (ESC). Eur Heart J. 2010;31:2369-2429.

12) Ruff CT, Giugliano RP, Braunwald E, Hoffman EB, Deenadayalu N, Ezekowitz MD, Camm AJ, Weitz JI, Lewis BS, Parkhomenko A, Yamashita T, Antman EM. Comparison of the efficacy and safety of new oral anticoagulants with warfarin in patients with atrial fibrillation: a meta-analysis of randomised trials. Lancet. 2014:383:955-962.

13) Hart RG, Pearce LA, Aguilar MI. Meta-analysis: antithrombotic therapy to prevent stroke in patients who have nonvalvular atrial fibrillation. Ann Intern Med. 2007;146:857-867.

14) Camm AJ, Accetta G, Ambrosio G, Atar D, Bassand JP, Berge E, Cools F, Fitzmaurice DA, Goldhaber SZ, Goto S, Haas S, Kayani G, Koretsune Y, Mantovani LG, Misselwitz F, Oh S, Turpie AG, Verheugt FW, Kakkar AK; GARFIELD-AF Investigators. Evolving antithrombotic treatment patterns for patients with newly diagnosed atrial fibrillation. Heart. 2017;103:307-314.

15) Gadsbøll K, Staerk L, Fosbøl EL, Sindet-Pedersen C, Gundlund A, Lip GYH, Gislason GH, Olesen JB. Increased use of oral anticoagulants in patients with atrial fibrillation: temporal trends from 2005 to 2015 in Denmark. Eur Heart J. 2017;38:899-906.

16) Huisman MV, Rothman KJ, Paquette M, Teutsch C, Diener HC,
Dubner SJ, Halperin JL, Ma CS, Zint K, Elsaesser A, Bartels DB, Lip GY; GLORIA-AF Investigators. The Changing Landscape for Stroke Prevention in AF: Findings From the GLORIA-AF Registry Phase 2.J Am Coll Cardiol. 2017;69:777-785.

17) Oh S, Goto S, Accetta G, Angchaisuksiri P, Camm AJ, Cools F, Haas S, Kayani G, Koretsune Y, Lim TW, Misselwitz F, van Eickels M, Kakkar AK; GARFILED-AF Investigators. Vitamin K antagonist control in patients with atrial fibrillation in Asia compared with other regions of the world: Real-world data from the GARFIELD-AF registry. Int J Cardiol. 2016;223:543-547.

18) Lee SR, Choi EK, Han KD, Cha MJ, Oh S, Lip GYH. Temporal trends of antithrombotic therapy for stroke prevention in Korean patients with non-valvular atrial fibrillation in the era of non-vitamin K antagonist oral anticoagulants: A nationwide population-based study. PLoS One. 2017;12:e0189495.

19) Go AS, Hylek EM, Phillips KA, Chang Y, Henault LE, Selby JV, Singer DE. Prevalence of diagnosed atrial fibrillation in adults: national implications for rhythm management and stroke prevention: the AnTicoagulation and Risk Factors in Atrial Fibrillation (ATRIA) Study. JAMA. 2001;285:2370-2375.

20) Jeong JH. Prevalence of and risk factors for atrial fibrillation in Korean adults older than 40 years. J Korean Med Sci. 2005;20:26-30.

21) Lee KS, Choi SJ, Park SH, Kim HI, Min H, Park HY. Prevalence of atrial fibrillation in middle-aged people in Korea: the Korean genome and epidemiology study, Korean Circ J. 2008;38:610-605.

22) Son MK, Lim NK, Cho MC, Park HY. Incidence and risk factors for atrial fibrillation in Korea: the National Health Insurance Service Database (2002-2010). Korean Circ J. 2016;46:515-521.

23) Lee H, Kim TH, Baek YS, Uhm JS, Park HN, Lee MH, Joung B. The trends of atrial fibrillation-related hospital visit and cost, treatment pattern and mortality in Korea: 10-year nationwide sample cohort data. Korean Circ J.2017;47:56-64.

24) Inoue $H$, Fujiki $A$, Origasa $H$, Ogawa $S$, Okumura $K$, Kubota I, Aizawa Y, Yamashita T, Atarashi H, Horie M, Ohe T, Doi Y, Shimizu A, Chishaki A, Saikawa T, Yano K, Kitabatake A, Mitamura H, Kodama I, Kamakura S. Prevalence of atrial fibrillation in the general population of Japan: an analysis based on periodic health examination. Int J Cardiol. 2009;137:102-107.

25) Zhou Z, Hu D. An epidemiology study on the prevalence of atrial fibrillation in the Chinese population of mainland China. J Epidemiol. 2008;18:209-216.

26) Kishore A, Vail A, Majid A, Dawson J, Lees KR, Tyrrell PJ, Smith 
CJ. Detection of atrial fibrillation after ischemic stroke or transient ischemic attack: a systematic review and meta-analysis. Stroke. 2014; 45:520-526.

27) Leyden JM, Kleiniq TJ, Newbury J, Castle S, Cranefield J, Anderson CS, Crotty M, Whitford D, Jannes J, Lee A, Greenhill J. Adelaide stroke incidence study: declining stroke rates but many preventable cardioembolic strokes. Stroke. 2013;44:1226-1231.

28) Lee SR, Choi EK, Han KD, Cha MJ, Oh S. Current prevalence of atrial fibrillation according to the regions and socioeconomic status in Korean population. KSC 2017 Abstract No.610038.

29) January CT, Wann LS, Alpert JS, Calkins H, Cigarroa JE, Cleveland JC Jr, Conti JB, Ellinor PT, Ezekowitz MD, Field ME, Murray KT, Sacco RL, Stevenson WG, Tchou PJ, Tracy CM, Yancy CW; American College of Cardiology/American Heart Association Task Force on Practice Guidelines. 2014 AHA/ACC/HRS guideline for the management of patients with atrial fibrillation: executive summary: a report of the American College of Cardiology/American Heart Association Task Force on practice guidelines and the Heart Rhythm Society. J Am Coll Cardiol. 2014;64: e1-76.

30) Kirchhof P, Benussi S, Kotecha D, Ahlsson A, Atar D, Casadei B, Castella M, Diener HC, Heidbuchel H, Hendriks J, Hindricks G, Manolis AS, Oldgren J, Popescu BA, Schotten U, Van Putte B, Vardas P, Agewall S, Camm J, Baron Esquivias G, Budts W, Carerj S, Casselman F, Coca A, De Caterina R, Deftereos S, Dobrev D, Ferro JM, Filippatos G, Fitzsimons D, Gorenek B, Guenoun M, Hohnloser SH, Kolh P, Lip GY, Manolis A, McMurray J, Ponikowski P, Rosenhek R, Ruschitzka F, Savelieva I, Sharma S, Suwalski P, Tamargo JL, Taylor CJ, Van Gelder IC, Voors AA, Windecker S, Zamorano JL, Zeppenfeld K. 2016 ESC Guidelines for the management of atrial fibrillation developed in collaboration with EACTS. Eur Heart J. 2016;37: 2893-2962.

31) Jung BC, Kim NH, Nam GB, Park HW, On YK, Lee YS, Lim HE, Joung B, Cha TJ, Hwang GS, Oh S, Kim JS. The Korean Heart Rhythm Society's 2014 Statement on antithrombotic therapy for patients with nonvalvular atrial fibrillation: Korean Heart Rhythm Society. Korean Circ J. 2015;45: 9-19.

32) Olesen JB, Lip GY, Hansen ML, Hansen PR, Tolstrup JS, Lindhardsen J, Selmer C, Ahlehoff O, Olsen AM, Gislason GH, TorpPedersen C. Validation of risk stratification schemes for predicting stroke and thromboembolism in patients with atrial fibrillation: nationwide cohort study. BMJ. 2011;342:d124.

33) Chao TF, Liu CJ, Wang KL, Lin YJ, Chang SL, Lo LW, Hu YF, Tuan TC, Chen TJ, Lip GY, Chen SA. Using the $\mathrm{CHA}_{2} \mathrm{DS}_{2}-\mathrm{VASc}$ score for refining stroke risk stratification in 'low-risk' Asian patients with atrial fibrillation. J Am Coll Caridol. 2014;64:1658-1665.

34) Guo Y, Apostolakis S, Blann AD, Wang H, Zhao X, Zhang Y, Zhang D, Ma J, Wang Y, Lip GY. Validation of contemporary stroke and bleeding risk stratification scores in non-anticoagulated Chinese patients with atrial fibrillation. Int J Cardiol. 2013;168:904-909.

35) Tomita H, Okumura K, Inoue H, Atarashi H, Yamashita T, Origasa H, Tsushima E; J-RHYTHM Registry Investigators. Validation of risk scoring system excluding female sex from $\mathrm{CHA}_{2} \mathrm{DS}_{2}$-VASc in Japanese patients with nonvalvular atrial fibrillation - subanalysis of the J-RHYTHM registry. Circ J. 2015;79:1719-1726.

36) Hung Y, Chao TF, Liu CJ, Tuan TC, Lin YJ, Chang SL, Lo LW, Hu YF, Liao JN, Chung FP, Lin WY, Lin WS, Cheng SM, Chen TJ, Lip GY, Chen SA. Is an oral anticoagulant necessary for young atrial fibrillation patients with a $\mathrm{CHA}_{2} \mathrm{DS}_{2}$-VASc score of 1 (men) or 2 (women)? J Am Heart Asssoc. 2016;5(10). pii: 3003839.

37) Chao TF, Lip GY, Liu CJ, Tuan TC, Chen SJ, Wang KL, Lin YJ, Chang SL, Lo LW, Hu YF, Chen TJ, Chiang CE, Chen SA. Validation of a modified $\mathrm{CHA}_{2} \mathrm{DS}_{2}$-VASc score for stroke risk stratification in Asian patients with atrial fibrillation: a nationwide cohort study. Stroke. 2016;47:2462-2469.

38) Kang SH, Choi EK, Han KD, Lee SR, Lim WH, Cha MJ, Cho Y, Oh IY, Oh S. Risk of ischemic stroke in patients with non-valvular atrial fibrillation not receiving oral anticoagulants - Korean nationwide population-based study. Circ J. 2017;81:1158-1164.

39) Kim TH, Yang PS, Uhm JS, Kim JY, Pak HN, Lee MH, Joung B, Lip GYH. $\mathrm{CHA}_{2} \mathrm{DS}_{2}$-VASc score (congestive heart failure, hypertension, age $\geq 75$ [doubled], diabetes mellitus, prior stroke or transient ischemic attack [doubled], vascular disease, age 65-74, female) for stroke in Asian patients with atrial fibrillation: a Korean nationwide sample cohort study. Stroke. 2017;48:1524-1530.

40) Lip GY, Frison L, Halperin JL, Lane DA. Identifying patients at high risk for stroke despite anticoagulation: a comparison of contemporary stroke risk stratification schemes in an anticoagulated atrial fibrillation cohort. Stroke. 2010;41:2731-2718.

41) Chao TF, Liu CJ, Tuan TC, Chen SJ, Wang KL, Lin YJ, Chang SL, Lo LW, Hu YF, Chen TJ, Chiang CE, Chen SA. Comparisons of $\mathrm{CHADS}_{2}$ and $\mathrm{CHA}_{2} \mathrm{DS}_{2}$-VASc scores for stroke risk stratification in atrial fibrillation: Which scoring system should be used for Asians? Heart Rhythm. 2016;13:46-53.

42) Suzuki S, Yamashita T, Okumura K, Atarashi H, Akao M, Ogawa $\mathrm{H}$, Inoue $\mathrm{H}$. Incidence of ischemic stroke in Japanese patients with atrial 
fibrillation not receiving anticoagulation therapy - pooled analysis of the Shinken Dababase, J-RHYTHM Registry, and Fushimi AF Registry. Circ J. 2015;79:432-438.

43) Eckman MH, Singer DE, Rosand J, Greenberg SM. Moving the tipping point: the decision to anticoagulated patients with atrial fibrillation. Circ Cardiovasc Qual Outcomes. 2011;4:14-21.

44) Freedman B, Potpara TS, Lip GY. Stroke prevention in atrial fibrillation. Lancet. 2016;388:806-817.

45) Bungard TJ, Ghali WA, Teo KK, McAlister FA, Tsuyuki RT. Why do patients with atrial fibrillation not receive warfarin? Arch Intern Med. 2000;160:41-46

46) Ogilvie IM, Newton N, Welner SA, Cowell W, Lip GY. Underuse of oral anticoagulants in atrial fibrillation: a systematic review. Am J Med. 2010;123:638-645.
47) Lee IH, Kim H, Je NK. Underutilization of warfarin for stroke prophylaxis in patients with atrial fibrillation or atrial flutter in Korea. Int J Cardiol. 2015;66:475-481.

48) Cha MJ, Choi EK, Han KD, Lee SR, Lim WH, Oh S, Lip GYH. Effectiveness and safety of non-vitamin $\mathrm{K}$ antagonist oral anticoagulants in Asian patients with atrial fibrillation. Stroke. 2017;48:3040-3048.

49) Camm AJ, Lip GY, De Caterina R, Savelieva I, Atar D, Hohnloser SH, Hindricks G, Kirchhof P; ESC Committee for Practice Guidelines (CPG). 2012 focused update of the ESC Guidelines for the management of atrial fibrillation: an update of the 2010 ESC Guidelines for the management of atrial fibrillation. Developed with the special contribution of the European Heart Rhythm Association. Eur Heart J. 2012;33:2719-2747. 